\title{
Ultimate Strength of Steel Panels and Stiffened Plates with Longitudinal Through-thickness Cracks under Compression
}

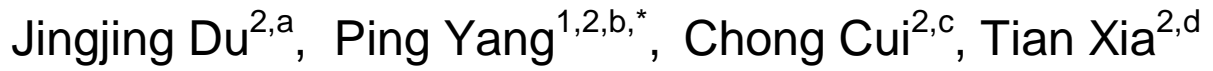 \\ ${ }^{1}$ Key Laboratory of High Performance Ship Technology of Ministry of Education, Wuhan University \\ of Technology, Wuhan 430063, Hubei, P. R. China \\ ${ }^{2}$ Departments of Naval Architecture, Ocean and structural Engineering, School of Transportation, \\ Wuhan University of Technology, Wuhan 430063, Hubei, P. R. China

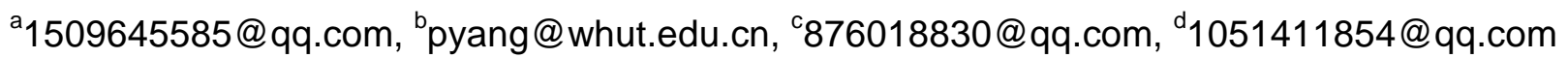 \\ * Corresponding author
}

Keywords: ultimate strength, longitudinal through-thickness crack, nonlinear finite element analysis, initial defect, stiffened plate

Abstract: A series of nonlinear finite element analysis for unstiffened and stiffened plates with initial defect is carried out by ANSYS software. The ultimate strength of steel panels and stiffened plates with longitudinal through-thickness cracks under longitudinal compression is studied in this paper. The influence of mesh size, initial deflections of plate and stiffeners to ultimate strength is considered in the numerical analyses. Comparisons between the results by the paper and those from the experiment are made. The effects of crack position, plate thickness on ultimate strength are investigated and discussed for unstiffened plates. The different increasing values of the ultimate strength contributed by adding plate thickness, stiffeners with same steel weight, with crack either in plate or in plate-stiffener connection are compared. Finally, some conclusions are drawn with practical significance to engineering.

\section{Introduction}

Traditional method of hull structural strength assessment is allowable stress method based on linear elastic theory. It is ruled by specification that the maximum stress values of the ship structural components are no more than the allowable stress values under all kinds of working conditions. However, the maximum carrying capacity and safety margin of ship structure can't be determined by traditional method for evaluating the structural strength. Therefore, more and more attention is paid to the ultimate strength of ship structure. A complete method of predicting the ultimate bending moment of the ship hull girder is established. And the NFEM results are compared with theoretical ones for the validation of the method ${ }^{[1]}$. In engineering, a complete set of method to calculate buckling and ultimate strength of stiffened plate has been established, which has been compared with the dates in CSR $^{[2]}$. In ship structures, cracks may be produced in the process of manufacturing and welding operations, and reduce the structure bearing capacity, which affects the safety of the ship structure. Nowadays, studies of the cracks are mainly focused on crack initiation and crack propagation life of the structure under cyclic loading rather than the loss of ultimate bearing capacity caused by the cracks. Therefore, researches on the ultimate strength of the structure with cracks are meaningful to engineering practice with regard to the safety of ship structures. Through a lot of efforts, theoretical models for predicting the ultimate strength of cracked plate elements under axial compression or tension are developed ${ }^{[3]}$. Nonlinear finite element method is used in this paper. First, appropriate mesh size of the models are selected. Second, study ${ }^{[4]}$ indicates crack location can significantly affects the ultimate strength characteristics of unstiffened and stiffened plate elements subjected to axial compressive action. So, the reduction characteristics of ultimate strength of ship plates with cracks in different locations are compared. Besides, the influence of plate thickness, stiffener, and crack location on the ultimate strength of ship structure is studied. Finally, some insights and findings developed in this study are discussed. 


\section{Models and Parameters about the Nonlinear Finite Element Analysis}

Nomenclatures of the important parameters involved in this paper are listed in Table 1. Element SHELL181 with four nodes in ANSYS ${ }^{[5]}$ is adopted to simulate the finite element models, and finer mesh is used around the crack in plate and stiffener, as shown in Figure 1. Longitudinal compression is applied to the short sides of the plate with the four sides simply supported and straight-line kept. Crack propagation under axial compression is not taken into account in this paper.

Table 1 Nomenclatures of the important parameters involved in this paper

\begin{tabular}{|c|c|c|c|}
\hline$a$ & plate length,580mm & $E$ & Young's modulus, $197500 \mathrm{MPa}$ \\
\hline$b$ & plate width, $500 \mathrm{~mm}$ & $v$ & Poisson's ratio, 0.3 \\
\hline$t$ & plate thickness & $\beta$ & Plate slenderness parameter, $\beta=b / t \sqrt{\sigma_{Y} / E}$ \\
\hline$h$ & stiffener height & $w_{0}$ & initial distortion \\
\hline$t_{l}$ & stiffener thickness & $X-, Y$ & Cartesian coordinates of the plate \\
\hline$c$ & half length of the crack, $125 \mathrm{~mm}$ & $\sigma_{Y}$ & yield stress of material, 245.5MPa \\
\hline$m$ & buckling mode half wave number & $\sigma_{u}$ & Ultimate strengths of the plates \\
\hline
\end{tabular}
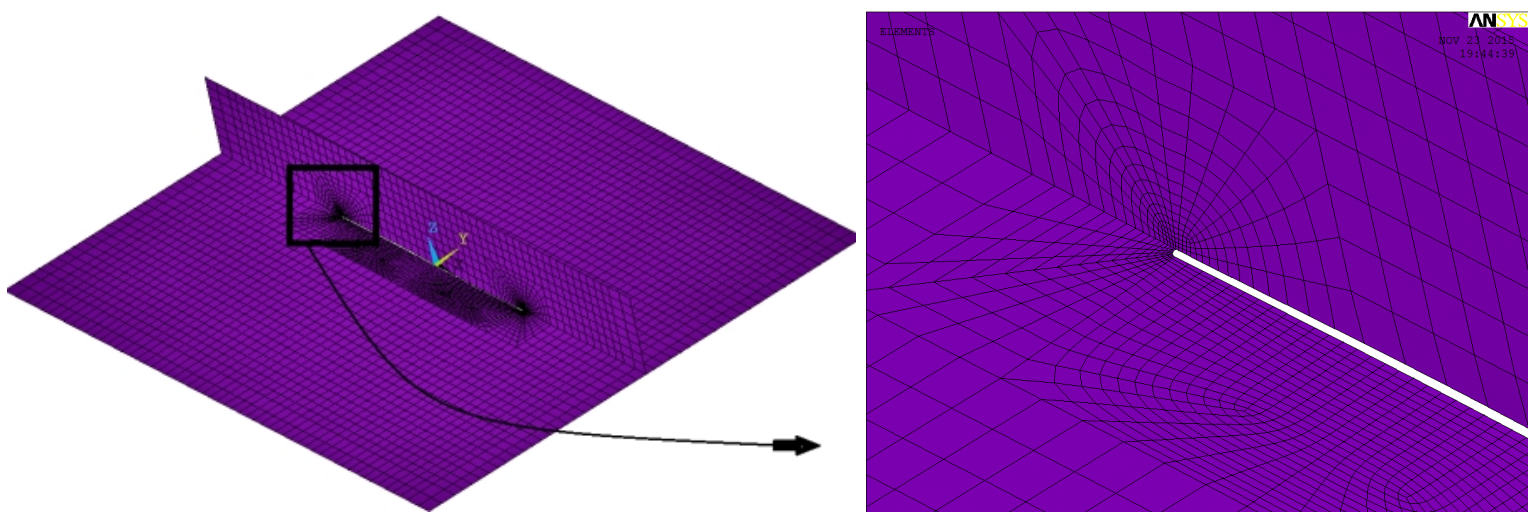

Fig. 1. Finer mesh around the crack

Initial deformation refers to the displacement difference between the real and the ideal structures. It's mainly produced by welding, thus called as welding deformation, which can be made up by the shape and the deflection amplitude of the deformation. Initial deformation of the stiffened plate can be divided into two parts: the initial deformation of the plate panel and the stiffener (including column-type initial deformation and side-ways initial deformation).

The calculation formulas for initial deformation and amplitude ruled in stiffened plate calibration calculation of ISSC2012 are used in this paper, and the formulas for the initial deformation of stiffened plate are as follows ${ }^{[6]}$ :

(1) initial deformation of the plate:

$$
w_{\text {opt }}=A_{0} \sin \frac{m \pi x}{a} \sin \frac{\pi y}{b} .
$$

(2) column-type initial deformation of the stiffener:

$$
w_{O C}=B_{0} \sin \frac{\pi x}{a} \sin \frac{\pi y}{B} .
$$

(3) side-ways initial deformation of the stiffener:

$$
w_{o s}=C_{0} \frac{z}{h_{w}} \sin \frac{\pi x}{a} .
$$

Where $A_{0}, B_{0}, C_{0}$ represent the three maximum deflection amplitude values, respectively, which are shown in Table 2. $a$ is spacing between adjacent transverse frames, $b$ is spacing between adjacent longitudinal stiffeners, $B$ is width of the stiffened plate, $h_{w}$ is height of the stiffener. 
Table 2 Initial deflection amplitude values

\begin{tabular}{|c|c|c|c|}
\hline maximum amplitude values & $A_{0}$ & $B_{0}$ & $C_{0}$ \\
\hline function & $0.1 \beta^{2} t$ & $0.0015 a$ & $0.0015 a$ \\
\hline
\end{tabular}

Eigenvalue buckling analysis is carried out to simulate initial deformation of plates and stiffened plates. First buckling mode of the plate or stiffened plate is chosen to get the initial deformation of the plate or stiffened plate ${ }^{[7]}$. With the same imperfection amplitude, the shape of the column-type initial deflection of stiffeners affects significantly the collapse shape, but only slightly the ultimate strength and the mode of collapse of the stiffened panels ${ }^{[8]}$.

\section{Nonlinear Finite Element Analysis}

The size of all the plates in this paper is $580 \mathrm{~mm} \times 500 \mathrm{~mm}$. The length and width of the longitudinal crack is $250 \mathrm{~mm}$ and $3 \mathrm{~mm}$ respectively. The study is carried out from the four aspects as follows: selection of the mesh size, the influence of crack location to the ultimate strength of plate, measures to improve the ultimate strength, and the influence of crack location to the ultimate strength of stiffened plate. Therefore, 11 finite element models are selected and established. The descriptions about the finite element models are shown in Table 3.

Selection of the Mesh Size. Through the comparison between mesh size $20 \mathrm{~mm} \times 20 \mathrm{~mm}$ (model-1) and mesh size $10 \mathrm{~mm} \times 10 \mathrm{~mm}$ (model-2) as shown in Figure 2, the ultimate strength values of these models is $130.48 \mathrm{MPa}$ and $129.98 \mathrm{MPa}$ respectively. It can be found that the variation of the ultimate strength is very small as $0.38 \%$ after refining the mesh. Therefore, these two mesh sizes are fine enough to achieve accurate results. However, mesh size $10 \mathrm{~mm} \times 10 \mathrm{~mm}$ is chosen in this paper to obtain more accurate results.

Influence of Crack Location to the Ultimate Strength of Plate. Ultimate strength will be reduced by cracks, based on that ultimate strength values of model-1 and model- 2 with crack are less than model-10 without crack in Figure 2. However, crack location is often uncertain in ship and marine engineering structures. Four different and typical longitudinal crack locations are studied in this paper, as shown in Figure 3. Through comparing the calculated ultimate strength values of center-crack (model-2), end-crack (model-3), one-edge-crack (model-4), and two-edge-crack (model-5) shown in Figure 4, it can be found that the end-crack decreases the ultimate strength more than the center-crack, but less than the edge-crack. The ultimate strength of the two-edge-crack is decreased by $52.35 \%$ that is larger than the one-edge-crack. The calculated ultimate strength values for the different four crack locations are shown in Table 4.

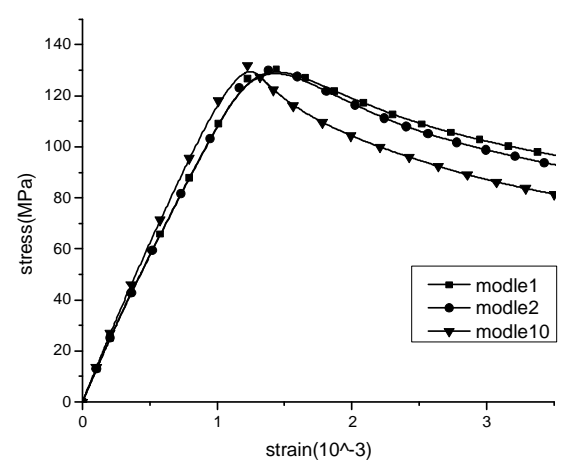

Fig.2. Influence of crack location to ultimate strength

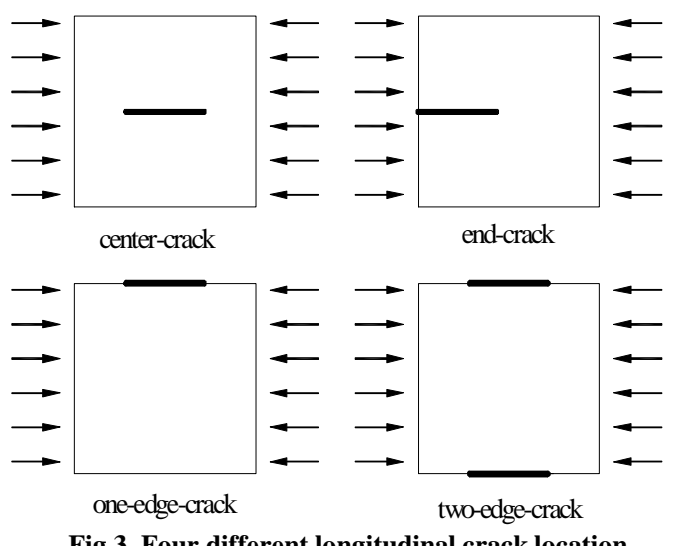

Fig.3. Four different longitudinal crack location 
Table 3 Descriptions of the analyzed finite element models

\begin{tabular}{|c|c|c|c|}
\hline Model & Description and figure & Model & Description and figure \\
\hline Model-1 & $\begin{array}{l}\text { The thickness of the plate with center-crack is } 4.4 \mathrm{~mm} \text {. Mesh } \\
\text { size is } 20 \mathrm{~mm} * 20 \mathrm{~mm} \text {. }\end{array}$ & Model-7 & $\begin{array}{l}\text { A stiffener }-80 * 2.5 \text { is added to the longitudinal section in } \\
\text { center plane based on model-2. }\end{array}$ \\
\hline Model-2 & $\begin{array}{l}\text { The thickness of the plate with center-crack is } 4.4 \mathrm{~mm} \text {. Mesh } \\
\text { size is } 10 \mathrm{~mm} * 10 \mathrm{~mm} \text { 。 }\end{array}$ & Model-8 & $\begin{array}{l}\text { Two stiffeners }-40 * 2.5 \text { are added to the longitudinal section in } \\
\text { about } 1 / 4 \mathrm{~b} \text { plane based on model- } 2\end{array}$ \\
\hline Model-3 & The thickness of the plate with end-crack is $4.4 \mathrm{~mm}$. & Model-9 & $\begin{array}{l}\text { The plate thickness is } 4.4 \mathrm{~mm} \text {, with a cracked stiffener }-80 * 2.5 \\
\text { on the longitudinal section in center plane. }\end{array}$ \\
\hline Model-4 & The thickness of the plate with one-edge-crack is $4.4 \mathrm{~mm}$. & Model-10 & The thickness of the plane without crack is $4.4 \mathrm{~mm}$. \\
\hline Model-5 & The thickness of the plate with two-edge-crack is $4.4 \mathrm{~mm}$. & Model-11 & The plate thickness is $4.4 \mathrm{~mm}$, and the stiffener is $-80 * 2.5$. \\
\hline Model-6 & The thickness of the plate with center-crack is $4.8 \mathrm{~mm}$. & & \\
\hline
\end{tabular}


Table4 The calculated ultimate strength (MPa) for the different four crack locations

\begin{tabular}{|c|c|c|}
\hline Model & Ultimate strength & Difference compared with model-10 (\%) \\
\hline Model-10 & 131.93 & - \\
\hline Model-2 & 129.98 & 1.48 \\
\hline Model-3 & 124.00 & 6.00 \\
\hline Model-4 & 100.04 & 24.16 \\
\hline Model-5 & 62.87 & 52.35 \\
\hline
\end{tabular}

Paik performed experiments on the ultimate strength of steel plates with longitudinal cracks under axial compression in $2007^{[9]}$, which have the same plate and crack sizes to model-2, model-3, model-4, model-5 and model-10 in this paper. Intact-1 (or Intact-2), Crack-C3, Crack-E1, Crack-G1 and Crack-G2 in the experiments is same to model-10, model-2, model-3, model-4, model-5 in this paper respectively. The comparison of ultimate strength values between the experiment and this paper is shown in Table 5. We can find that the ultimate strength of model-10, model-2, and model-3 has significant difference to the experiment results, while model-4 and model-5 coincide with the experiment results. In Paik's study ${ }^{[10]}$ of nonlinear finite element method corresponded to the experiment, we can also find that the ultimate strength of Crack-C3 and Crack-E1 has significant difference between residual stress with and without consideration, but the influence of welding residual stress to ultimate strength is very small for Crack-G1. So the influence of welding residual stress can be ignored in the nonlinear finite element analysis. Therefore, the ultimate strength calculated in this paper is reasonable.

Table 5 Difference of ultimate strength (MPa) between calculation and the experiment

\begin{tabular}{|c|c|c|c|}
\hline & Experiment & Calculation & Difference $(\%)$ \\
\hline Intact-1/model-10 & 105.28 & 131.93 & 25.31 \\
\hline Crack-C3/model-2 & 97.64 & 129.98 & 33.12 \\
\hline Crack-E1/model-3 & 103.65 & 124.00 & 19.63 \\
\hline Crack-G1/model-4 & 97.60 & 100.04 & 2.50 \\
\hline Crack-G2/model-5 & 62.37 & 62.87 & 0.80 \\
\hline
\end{tabular}

Measures to Improve the Ultimate Strength. Method to improve the ultimate strength of plate is to increase the plate thickness or add stiffener to the plate in general, which all increase the amount of steel. So the two methods are compared to get out which one increases the ultimate strength more in case of increasing the same amount of steel. In this paper, the volume of the steel increases by $116000 \mathrm{~mm}^{3}$, when only the thickness of the plate increases from $4.4 \mathrm{~mm}$ (model-2) to $4.8 \mathrm{~mm}$ (model-6). The increased steel is used to add one stiffener $-80 * 2.5$ (model-7) or two stiffeners $-40 * 2.5$ (model-8) on the plate. The influence of increasing thickness or adding stiffener on the ultimate strength of the cracked plate is studied by calculating the ultimate strength values of model- 6 , model-7, and model-8, which is shown in Figure 5. We can find that all the methods improve the ultimate strength, while adding a stiffener increases more than increasing plate thickness, but less than adding two stiffeners that reaches to $26.06 \%$, as shown in Table 6 . 


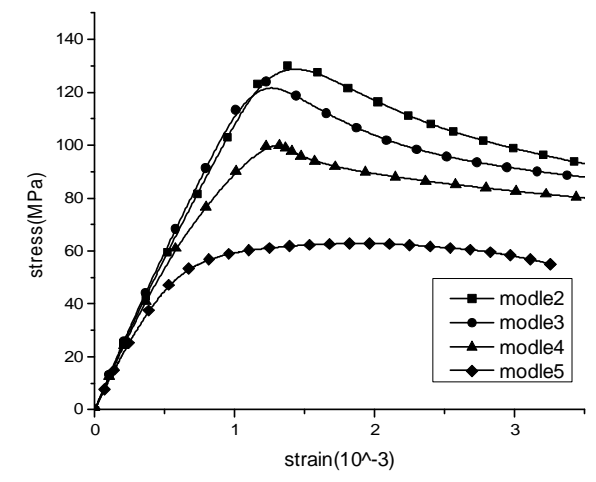

Fig.4. Influence of crack location to ultimate strength

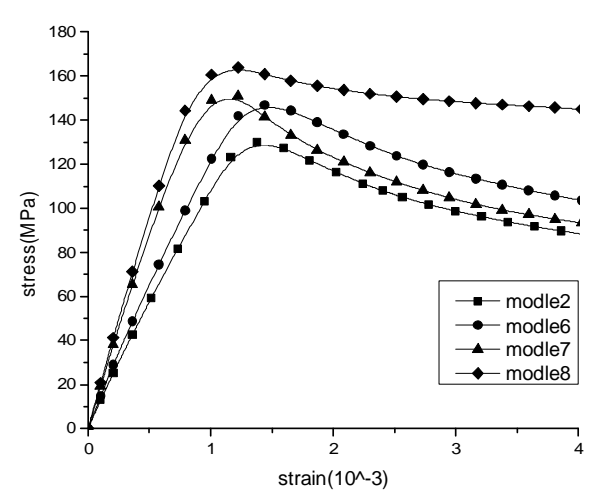

Fig.5. Measures to improve the ultimate strength

Table 6 The influence of increasing thickness or adding stiffener on ultimate strength (MPa)

\begin{tabular}{|c|c|c|}
\hline Model & Ultimate strength & Increase compared to model-2 (\%) \\
\hline Model-2 & 129.98 & - \\
\hline Model-6 & 146.88 & 13.00 \\
\hline Model-7 & 150.80 & 16.02 \\
\hline Model-8 & 163.85 & 26.06 \\
\hline
\end{tabular}

Influence of Crack Location to the Ultimate Strength of Stiffened Plate. Stiffened Plates are the basic structural members in ship structures. However, the crack location in the stiffened plate is also randomly uncertainty. Therefore, the crack locations in plate (model-7) and stiffener (model-9) are chosen in this paper. The influence of crack location to the ultimate strength of stiffened plate is studied, and the results of nonlinear finite element analysis are shown in Figure 6.

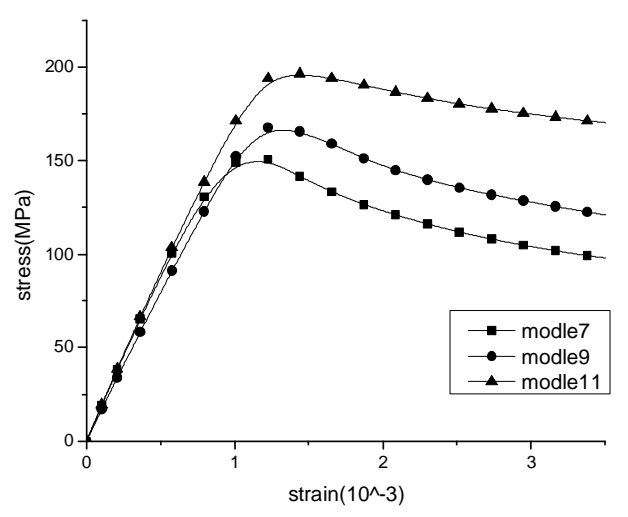

Fig.6. Influence of crack location on the ultimate strength of stiffened plate

Through the comparison of ultimate strength values among model-7, model-9 and model-11 (without crack), we can find that the ultimate strength of crack located in the plate decreases significant than that in the stiffener, which reaches to $23.31 \%$ as shown in Table 7 .

Table 7 Influence of crack location on the ultimate strength (MPa) of stiffened plate

\begin{tabular}{|c|c|c|}
\hline model & ultimate strength & Decrease compared to model-11 $(\%)$ \\
\hline Model-11 & 196.63 & - \\
\hline Model-7 & 150.80 & 23.31 \\
\hline Model-9 & 167.81 & 14.66 \\
\hline
\end{tabular}




\section{Conclusions}

Ultimate strength of steel panels and stiffened plates with longitudinal through-thickness cracks and initial deformation under compression is studied in this paper. The nonlinear finite element analysis is carried out from the four aspects: selection of the mesh size, the influence of crack location to the ultimate strength of plate, measures to improve the ultimate strength, and the influence of crack location to the ultimate strength of stiffened plate. And some useful conclusions have been derived:

1) The order of the ultimate strength values for different crack locations is that: center-crack > end-crack > one-edge-crack > two-edge-crack. So, edge-crack should be paid much attention and avoided.

2) Adding stiffener increases the ultimate strength more than increasing plate thickness. So, the measure of adding stiffener should be adopted to improve the ultimate strength of cracked structures from the viewpoint of economics.

3) The ultimate strength of crack located in the plate decreases more than that in the stiffener. So, the crack in plate should be paid more attention to ensure the safety of ship structures with regarding to the load bearing capacity.

\section{Acknowledgements}

This work was financially supported by the National Natural Science Foundation of China (No. 51279150).

\section{References}

[1] Zhou Haizhong. The ultimate strength analysis of the ship structures based on NFEM [D]. Harbin Engineering University, 2010.

[2] Wan Yulong, Zhu Xuguang. Study on finite element analysis about buckling and ultimate strength of stiffened plate [J]. Ship and Ocean Engineering, 2013.

[3] Paik J K. Ultimate strength of cracked plate elements under axial compression or tension [J]. Thin-Walled Structures, 2005, 43 (2005) 237-272.

[4] Abbas Bayatfar. Residual ultimate strength of cracked steel unstiffened and stiffened plates under longitudinal compression [J]. Thin-Walled Structures, 2014, 84(2014)378-392.

[5] ANSYS,2007. User's Manual (version 11.0). ANSYS Inc.

[6] Committee III.1. Ultimate Strength Report. Proceedings of The 18th International Ship and Offshore Structures Congress, Vol.1:285-363

[7] SHAN Cheng Wei. Nonlinear finite element analysis for the ultimate strength of stiffened plates under cyclic loading [D]. Wuhan University of Technology, 2013.

[8] Ming Cai $\mathrm{Xu}$. Comparisons of calculations with experiments on the ultimate strength of wide stiffened panels[J]. Marine Structures, 2013, 31 (2013) 82-101.

[9] Paik J K. Residual ultimate strength of steel plates with longitudinal cracks under axial compression-experiments [J]. Ocean Engineering, 2008, 35:1775-1783.

[10] Paik J K. Residual ultimate strength of steel plates with longitudinal cracks under axial compression-Nonlinear finite element method investigations [J]. Ocean Engineering, 2009, 36:266-276. 